\title{
In vitro evaluation of antioxidant, antineurodegenerative and antidiabetic activities of Ocimum basilicum L., Laurus nobilis L. leaves and Citrus reticulata Blanco peel extracts
}

\author{
Sonja Duletić-LauŠević ${ }^{1}$, Mariana OAløe ${ }^{1, *}$, ANd Ana Alimpić Aradski ${ }^{1}$ \\ ${ }^{1}$ University of Belgrade, Faculty of Biology, Institute of Botany and Botanical Garden “Jevremovac", Studentski trg 16, 11000 Belgrade, Serbia \\ *Corresponding author: marianao@bio.bg.ac.rs
}

Received: November 11, 2019

Accepted: December 5, 2019

Published on-line: December 9, 2019

Published: December 25, 2019

\begin{abstract}
Ocimum basilicum (sweet basil) and Laurus nobilis (bay leaves or laurel) have been used in traditional medicine for centuries, and also extensively employed as spices for adding aroma and flavor to various food products. Citrus reticulata (mandarin) is mainly used in food industry for juice production, while its peel as main byproduct contains high concentration of valuable substances. The samples were collected in Lastva Grbaljska (Montenegrin coast) and purchased from the market. Since the oxidative stress results in development of numerous diseases, among them neurodegeneration and diabetes, the antioxidant activity, antineurodegenerative and antidiabetic activities were analyzed, aiming to compare potential of plants cultivated under natural conditions and commercially purchased from the market, as well as to compare the effect of different solvents applied in the extraction process. Water, methanol and acetone extracts of leaves and peel were tested by DPPH and total reducing power (TRP) methods for determination of antioxidant activity, and by acetylcholinesterase (AChE) and $\alpha$ glucosidase inhibition assays for analyzing the other activities. Total phenolic (TPC) and flavonoid (TFC) contents were also determined. The acetonic extract of $L$. nobilis from Lastva showed the highest TPC, DPPH, TRP, and $\alpha$-glucosidase inhibition, while water extract of commercial L. nobilis exhibited the highest AChE inhibition. The leaves of $L$. nobilis are demonstrated to be promising antioxidant, antineurodegenerative and antidiabetic agent.
\end{abstract}

Key words: Ocimum basilicum, Laurus nobilis, Citrus reticulata, extracts, bioactivities

\author{
ABBREVIATIONS \\ AD - Alzheimer's disease \\ AChE - Acethylcholinesterase \\ AGLU - $\alpha$-glucosidase \\ DM - Diabetes mellitus \\ DPPH - 2,2-Diphenyl-1-picrylhydrazyl \\ TFC - Total flavonoid content \\ TPC - Total phenolic content \\ TRC - Total reducing power
}

\section{INTRODUCTION}

Free radicals are highly reactive species having unpaired electrons in their outermost shell leading to oxidative stress, which causes tissue damage and results in large number of diseases. Oxidative stress plays a major role in progression of neuro- logical diseases, such as Alzheimer's disease (AD) and also in diabetes mellitus (DM). When disbalance of the production of reactive oxygen species (ROS) and cellular antioxidant defenses appears, proteins and nuclear acids damages occur, having destructive effects in AD and DM (Reddy et al., 2009). Numerous molecular, clinical, epidemiological, etc. data supports a pathophysiological link between AD and DM (Ahmad et al., 2017). Cognitive decline related to DM is characterized by mild to moderate impairment, and an increased risk of developing AD and other forms of dementia (Toth, 2014). Considering the fact that AD and DM reach epidemic proportions, different approaches for their prevention and treatment are present among scientists worldwide. Natural products are extensively studied in the last decades for suppressing ROS production, and might be promising in AD and DM therapy. Antioxidants of natural or synthetic origin neutralize the effects of reactive oxygen species and thus help in preventing 
diseases. There is a growing interest both in various industrial sectors and among people worldwide towards the use of natural compounds obtained from plants in cosmetic, food and pharmaceutical industries which could represent alternatives to synthetic chemicals, because natural compounds have lesser environmental and human health impacts. Natural antioxidants can be taken up through diet as they are present in fruits, vegetables and spices which contain a large amount of flavonoids and antioxidant supplements that contribute to protection against different types of health problems (Hamid et al., 2010). The beneficial effects of medicinal plants in AD and DM have been confirmed in numerous studies (Bazzari and Bazzari, 2018; Nasri et al., 2015). Several species belonging to the family Lamiaceae are of high socio-economic value, having therapeutical, culinary, horticultural, ornamental or industrial applications due to the high content of bioactive phenolic compounds (Trivellini et al., 2016). The Lauraceae family comprises species which contain considerable concentrations of essential oils, including genera of high commercial value, such as cinnamomum, laurus and persea. Different kinds of Citrus fruits are used in food industry for fresh juice production, with the peel as the main waste fraction, which had been widely studied because of high content of numerous biologically active compounds including natural antioxidants such as phenolic acids and flavonoids (Xu et al., 2007). Ocimum basilicum L. (Lamiaceae), commonly known as sweet basil, is a perennial herb, native to Asia, Africa, South America, and the Mediterranean but widely cultivated in many countries (Grayer et al., 1996). This important medicinal plant and culinary herb has been used traditionally for treatment of anxiety, diabetes, cardiovascular diseases, headaches, nerve pain, cough, cold, fevers, headaches and migraines, insect bites, menstrual cramps, sinusitis, as an anticonvulsant, antiinflammatory and antithrombotic agent, and in a variety of digestive and neurodegenerative disorders (Purushothaman et al., 2018). Laurus nobilis L. (Laureaceae), commonly known as bay leaves or laurel, is a native plant from the Mediterranean region and is cultivated mainly in Europe and USA as an ornamental plant (Garg et al., 1992). It is widely used as a spicy fragrance and flavor in traditional meat dishes, stews and rice (Dias et al., 2014). Its leaves and extracts are used to suppress high blood sugar, fungal and bacterial infections, to treat eructation, flatulence and gastrointestinal problems and also exhibits anti-inflammatory, anticonvulsive, antiepileptic, cytotoxic, antioxidant and neuroprotective properties (Barla et al., 2007; Dias et al., 2014; Maajida Aafreen M et al., 2019; Pacifico et al., 2014). China is the most important centre of origin for the species of the genus Citrus (Zhang et al., 2014). Citrus species (Rutaceae) produce widely used fruits of high nutritional and industrial value, rich in flavonoid derivatives and polymethoxylated flavonoids, with different distribution in fruit parts (Nogata et al., 2006). Dried peel of Citrus reticulata Blanco is recorded in the Chinese Pharmacopeia as chenpi used for activation of vital energy and circulation, elimination of phlegm, disperse physical stagnation, etc., being good source of phenolics, especially of flavanone glycosides (Tumbas et al., 2010). The mentioned substances may play a role in the prevention of diabetes, cardiovascular and other diseases (Zhang et al., 2014). The main goal of this research was to compare bioactivities (antioxidant, antineurodegenerative and antidiabetic) of extracts of O. basilicum and L. nobilis leaves and C. reticulata peel obtained from plants cultivated under natural conditions in the Montenegro coastal region and commercially purchased from the market, and additionally to compare the influence of the different solvents applied in the extraction process.

\section{MATERIALS AND METHODS}

\subsection{Reagents and standards}

Methanol, ethanol and hydrochloric acid were obtained from Zorka Pharma, Šabac, Serbia. Gallic acid, ascorbic acid, acarbose, galanthamine, quercetin, 2-tert-butyl4-hydroxyanisole (BHA), 3,5-di-tert-butyl-4-hydroxytoluene (BHT), 2,2-diphenyl-1-picrylhydrazyl (DPPH), dimethylsulfoxide (DMSO), iron(III) chloride, sodium carbonate anhydrous $\left(\mathrm{Na}_{2} \mathrm{CO}_{3}\right)$, sodium bicarbonate $\left(\mathrm{NaHCO}_{3}\right)$ sodium phosphate dibasic, sodium dihydrogen phosphate dodecahydrate, sodium phosphate monobasic, sodium phosphate monobasic dihydrate, aluminum nitrate nonahydrate $\left(\mathrm{Al}\left(\mathrm{NO}_{3}\right)_{3} \times\right.$ $\left.9 \mathrm{H}_{2} \mathrm{O}\right)$, potassium acetate $\left(\mathrm{CH}_{3} \mathrm{COOK}\right)$, potassium hydrogen phosphate, potassium dihydrogen phosphate, pNPG (4nitrophenyl $\beta$-D-glucopyranoside), DTNB (5,5'-dithio-bis(2nitrobenzoic acid)), Trisma base, $\alpha$-glucosidase (from Saccharomyces cerevisiae) type I, acetylcholinesterase (from Electrophorus electricus), acetylcholine iodide and Folin-Ciocalteu reagent were purchased from Sigma-Aldrich, St. Louis, MO. Trichloroacetic acid and potassium ferricyanide were purchased from Superlab (Serbia), while sodium hydroxide was purchased from NRK inženjering (Serbia). Starch was purchased from Roth (Germany).

\subsection{Plant material}

Plants were cultivated in Lastva Grbaljska, near Budva (Montenegro). Leaves of Ocimum basilicum and Laurus nobilis were collected in August 2018, while Citrus reticulata fruits were collected in November 2017. Plant material was dried and kept in shade at room temperature for further processing The voucher specimens of L. nobilis and O. basilicum were deposited in the Herbarium of the Institute of Botany and Botanical Garden "Jevremovac", University of Belgrade, Faculty of Biology (BEOU; voucher No. 17510, and 17511). The commercially purchased basil and bay leaves are products of Premia (Serbia), while mandarins were purchased from the local market.

\subsection{Preparation of extracts}

Grinded plant material (5 g of O. basilicum and L. nobilis leaves and $10 \mathrm{~g}$ of $C$. reticulata peel) was extracted during $24 \mathrm{~h}$ at room temperature $(5 \% \mathrm{w} / \mathrm{v}$ and $10 \% \mathrm{w} / \mathrm{v}$, respectively) using acetone, methanol and hot water. The mixture was exposed to ultrasound $1 \mathrm{~h}$ before and after $24 \mathrm{~h}$ to improve the extraction process. Subsequently, extracts were filtered through filter paper (Whatman No.1) and evaporated under reduced pressure (Buchi rotavapor R-114). The obtained crude extracts were stored in a refrigerator at $+4{ }^{\circ} \mathrm{C}$ for further experiments. The yield of the extracts was calculated using the following equation:

$$
\text { Yield }(\%)=\frac{m}{M} \times 100
$$

where $m$ represents the mass of dry extract, while $M$ is the mass of the dry plant extract used for the extraction.

\subsection{Determination of total phenolic and total flavonoid con- tents}

Total phenolic content (TPC) of the plant extracts was performed applying the spectrophotometric procedure of Singleton and Rossi (1965). The reaction mixture was prepared by mixing $100 \mu \mathrm{L}$ of extract at the concentration of $0.5 \mathrm{mg} / \mathrm{mL}$ with $500 \mu \mathrm{L}$ of $10 \%$ Folin \& Ciocalteu's reagent dissolved in water. After $6 \mathrm{~min}, 400 \mu \mathrm{L}$ of $7.5 \%$ sodium carbonate was added. Blank contained distilled water instead of extracts. The absorbance was measured at $740 \mathrm{~nm}$ after $2 \mathrm{~h}$ incubation at room temperature, using Jenway 7315 UV/Visible spectrophotometer. The same procedure was repeated for the standard 
solution of gallic acid (GA). The phenolic content of the samples was calculated from the standard curve and expressed as mg GA equivalents per gram of dry extract, presented as mean \pm standard deviation.

Total flavonoid content (TFC) of the samples was measured spectrophotometrically using Jenway 7315 UV/Visible spectrophotometer, according to the procedure of Park et al. (1997). The reaction mixture was prepared by mixing $0.5 \mathrm{~mL}$ of extract at the concentration of $0.5 \mathrm{mg} / \mathrm{mL}$ with $2.05 \mathrm{~mL} 80 \%$ ethanol, $0.05 \mathrm{~mL} 10 \%\left(\mathrm{Al}\left(\mathrm{NO}_{3}\right)_{3} \times 9 \mathrm{H}_{2} \mathrm{O}\right)$, and $0.05 \mathrm{~mL} 1 \mathrm{M} \mathrm{CH}_{3} \mathrm{COOK}$. Blank contained $96 \%$ ethanol instead of extract. After $40 \mathrm{~min}$ of incubation at room temperature, the absorbance was measured at $415 \mathrm{~nm}$. The same procedure has been repeated for the $96 \%$ ethanol solution of quercetin (Q) in order to construct the calibration curve. The content of flavonoids in the samples was expressed as $\mathrm{mg} Q$ equivalents per gram of dry extract, as mean \pm standard deviation.

\subsection{Evaluation of antioxidant activity}

\subsubsection{DPPH assay}

DPPH free radical scavenging method (Blois, 1958) was used for the determination of antioxidant activity, with slight modification. In test tubes was added $100 \mu \mathrm{L}$ of extract at the concentration of $0.5 \mathrm{mg} / \mathrm{mL}$ and $900 \mu \mathrm{L}$ methanolic solution of DPPH $(40 \mu \mathrm{g} / \mathrm{mL})$. Methanol was used as blank, methanol with DPPH solution was used as negative control, while BHA, $\mathrm{BHT}$ and ascorbic acid were used as positive controls (standards). The absorbance was measured at $517 \mathrm{~nm}$ after 30 min in the dark at room temperature, using Jenway 7315 UV/Visible spectrophotometer. The decrease in absorption of DPPH was calculated as follows:

$$
\text { Inhibition of DPPH radical }(\%)=\frac{A_{\mathcal{c}}-A_{s}}{A_{\mathcal{C}}} \times 100
$$

where $A_{c}$ represents the absorbance of the negative control, while the absorbance of the test samples is labeled with $A_{s}$. The results are presented as percentage of DPPH inhibition \pm standard deviation.

\subsubsection{Total reducing power assay}

The total reducing power (TRP) was determined according to the method of Tusevski et al. (2014), with slight modifications. In the reaction mixture was added $100 \mu \mathrm{L}$ of sample at the concentration of $0.5 \mathrm{mg} / \mathrm{mL}, 200 \mu \mathrm{L}$ phosphate buffer $(0.2$ $\mathrm{M}, \mathrm{pH}$ 6.6) and $200 \mu \mathrm{L} 1 \%$ potassium ferricyanide. After the incubation $\left(20\right.$ minutes at $\left.50{ }^{\circ} \mathrm{C}\right), 200 \mu \mathrm{L} 10 \%$ trichloracetic acid, $200 \mu \mathrm{L}$ distilled water and $40 \mu \mathrm{L} 0.1 \%$ iron (III) chloride were added. Blank was prepared in the same manner, with the exception of adding $100 \mu \mathrm{L}$ of adequate solvent instead of sample. The absorbance was measured at $700 \mathrm{~nm}$ after the 10 minute incubation at room temperature, using Jenway 7315 $\mathrm{UV} /$ Visible spectrophotometer. The total reduction power of the samples was presented as $\mu \mathrm{mol}$ of ascorbic acid equivalents (AAE) per gram of dry extract ( $\mu \mathrm{mol} \mathrm{AAE} / \mathrm{g}$ dry extract).

\subsection{Antineurodegenerative activity}

Acethylcholinesterase (AChE) inhibitory activity assay was performed according to the procedure of Ellman et al. (1961), using 96-well plates. The reaction mixture (S) was prepared by adding $140 \mu \mathrm{L}$ of sodium-phosphate buffer $(0.1 \mathrm{M}, \mathrm{pH} 7), 20$ $\mu \mathrm{L}$ DTNB solution, $20 \mu \mathrm{L}$ sample (at the concentration of 0.5 $\mathrm{mg} / \mathrm{mL})$ and $20 \mu \mathrm{L}$ AChE solution $(5 \mathrm{U} / \mathrm{mL})$ in Tris-HCl buffer (20 mM, pH 7.5). The mixture without the sample was used as a control (C, sodium-phosphate buffer instead of sample), the mixture without the enzyme was used as blank for the extracts (B), while galanthamin was used as positive control (at the concentration of $0.1 \mathrm{mg} / \mathrm{mL}$ ). After 15 minutes at 25
${ }^{\circ} \mathrm{C}$, the reaction was initiated by adding $10 \mu \mathrm{L}$ of acetylcholine iodide. Absorbance was measured at $412 \mathrm{~nm}$, using Multiscan Sky Thermo Scientific, Finland. The percentage of inhibition was calculated by using the following equation:

Inhibition of acethylcholinesterase $(\%)=\frac{C-(S-B)}{C} \times 100$

\subsection{Antidiabetic activity}

Determination of $\alpha$-glucosidase inhibitory activity was performed according to the method of Wan et al. (2013), with slight modifications. Briefly, the same volumes $(20 \mu \mathrm{L})$ of phosphate buffer $(0.1 \mathrm{M}, \mathrm{pH} 6.9), \alpha$-glucosidase $(0.5 \mathrm{U} / \mathrm{mL})$ and samples (S) at the concentration of $0.5 \mathrm{mg} / \mathrm{mL}$ were preincubated for $5 \mathrm{~min}$ at $37^{\circ} \mathrm{C}$. After that, $20 \mu \mathrm{L}$ of pNPG $(15$ $\mathrm{mg} / 10 \mathrm{~mL}$ ) as substrate was added to the mixture and the incubation continued for another $20 \mathrm{~min}$ at $37^{\circ} \mathrm{C}$. At the end, the reaction was stopped by adding $80 \mu \mathrm{L}$ of $0.2 \mathrm{M}$ sodium carbonate and the absorbance was measured at $405 \mathrm{~nm}$ using Multiscan Sky Thermo Scientific, Finland. The control (C) contained buffer solution instead of sample, while blank (B) contained buffer solution instead of enzyme. Acarbose at the concentration of $0.1 \mathrm{mg} / \mathrm{mL}$ was used as a positive control. The percentage of inhibition of $\alpha$-glucosidase was calculated according to the following equation:

$$
\text { Inhibition of } \alpha \text {-glucosidase }(\%)=\frac{C-(S-B)}{C} \times 100
$$

\subsection{Statistical analysis}

All experimental measurements were carried out in triplicate and the results are expressed as the average of three measurements \pm standard deviation. To assess the potential effects of the solvent type, the results were subjected to one-way ANOVA, followed by Tukey's post-hoc test (the results were considered statistically significant at $\mathrm{P}<0.05$ level). Differences between localities for all observed parameters were estimated through Student's $t$-test $(\mathrm{P}<0.05)$. Pearson's correlation coefficients (r) were calculated among the investigated activities of extracts and phytochemical contents and presented according to Taylor (1990), where $\mathrm{r}<0.35,0.36<\mathrm{r}<0.67$ and $0.68<\mathrm{r}<1$ were considered weak, moderate and strong correlation, respectively. All statistical analyses were done using the software package STATISTICA v.10.0.

\section{RESULTS AND DISCUSSION}

\subsection{Yields, total phenolic and flavonoid contents of extracts}

The yields of extracts varied depending on the plant species, origin of plant material and applied solvent (Table 1). The highest extraction yields for $O$. basilicum leaves were achieved when water was used as an extraction solvent (10.08 and $10.54 \%$ ). Bomma et al. (2018) analyzed six Ocimum species and obtained yield for methanolic extracts of $O$. basilicum ranging from 0.98 to $1.44 \%$, while methanolic extracts in our research yielded 4.62 and $6.74 \%$. In the case of bay leaves, the yield of acetonic extract of commercial sample (31.06\%) was noticeable higher comparing to other samples. On the contrary, methanolic extracts of Moroccan bay leaves showed the highest yield (22\%) comparing to other applied solvents (Taroq et al., 2018). Mandarin peel showed the highest yield in methanolic extracts of both commercial and naturally cultivated samples (23.07 and 23.77\%) (Table 1). Senol et al. (2016) in the study of the ethanolic extracts of peels of $C$. reticulata cultivars obtained yields from 11.39 to $42.5 \%$. Safdar et al. (2017) tested mandarin peels with different extraction methods and extraction solvents, and achieved the highest yield 
Table 1. Yield and the total phenolic content (TPC) and flavonoid content (TFC) of the plant extracts

\begin{tabular}{|c|c|c|c|c|c|c|c|c|c|}
\hline \multirow[t]{3}{*}{ Species } & \multirow[t]{3}{*}{ Extract type } & \multicolumn{2}{|c|}{ Yield (\%) } & \multicolumn{2}{|c|}{$\mathrm{TPC}^{\mathrm{a}}$} & \multicolumn{4}{|c|}{ TFC } \\
\hline & & \multicolumn{2}{|l|}{$[\%]$} & \multicolumn{2}{|c|}{ [mg GAE/g] } & \multicolumn{4}{|c|}{ [mg QE/g] } \\
\hline & & Commercial & Lastva & Commercial & Lastva $^{b}$ & & Commercial & Lastva & \\
\hline \multirow[t]{3}{*}{ O. basilicum } & Acetonic & 2.18 & 3.26 & $28.52 \pm 1.42 \mathrm{~d}$ & $25.45 \pm 2.25 \mathrm{f}$ & & $31.97 \pm 2.70 \mathrm{a}$ & $44.83 \pm 3.22 \mathrm{a}$ & $t$ \\
\hline & Methanolic & 6.74 & 4.62 & $41.60 \pm 1.68 c$ & $34.94 \pm 3.00 \mathrm{e}$ & $t$ & $25.66 \pm 0.89 b$ & $32.06 \pm 1.35 b$ & $t$ \\
\hline & Aqueous & 10.08 & 10.54 & $50.08 \pm 3.17 b$ & $70.21 \pm 2.64 b$ & $t$ & $9.54 \pm 0.47 \mathrm{~d}$ & $13.52 \pm 0.79 d$ & \\
\hline \multirow[t]{3}{*}{ L. nobilis } & Acetonic & 31.06 & 5.5 & $75.98 \pm 5.40 \mathrm{a}$ & $83.84 \pm 0.49 a$ & $t$ & $6.43 \pm 0.05 \mathrm{e}$ & $27.31 \pm 0.90 c$ & $\dagger$ \\
\hline & Methanolic & 16.3 & 19.88 & $73.37 \pm 2.80 \mathrm{a}$ & $46.46 \pm 3.22 \mathrm{~cd}$ & $t$ & $13.58 \pm 0.05 c$ & $24.73 \pm 0.32 c$ & + \\
\hline & Aqueous & 10.54 & 13.96 & $56.57 \pm 2.73 b$ & $35.04 \pm 2.17 \mathrm{e}$ & $t$ & $7.02 \pm 0.32 \mathrm{de}$ & $6.90 \pm 0.61 \mathrm{e}$ & \\
\hline \multirow[t]{3}{*}{ C. reticulata } & Acetonic & 5.66 & 4.43 & $52.79 \pm 1.87 \mathrm{~b}$ & $52.40 \pm 2.89 c$ & & $13.61 \pm 0.11 \mathrm{c}$ & $13.05 \pm 0.23 \mathrm{~d}$ & \\
\hline & Methanolic & 23.07 & 23.77 & $34.62 \pm 1.19 \mathrm{~cd}$ & $43.00 \pm 0.93 \mathrm{~d}$ & + & $6.34 \pm 0.11 \mathrm{e}$ & $8.05 \pm 0.65 \mathrm{e}$ & \\
\hline & Aqueous & 12.85 & 6.69 & $28.36 \pm 1.19 \mathrm{~d}$ & $25.52 \pm 0.29 \mathrm{f}$ & + & $6.15 \pm 0.43 \mathrm{e}$ & $6.09 \pm 0.41 \mathrm{e}$ & \\
\hline
\end{tabular}

${ }^{a}$ Different letters denote statistical difference among means according to post-hoc Tuckey HSD test at level $\mathrm{P}<0.05$.

$\mathrm{b}+$ sign denote statistically significant difference between Commercial and Lastva mean values according to the Student's $t$-test $(\mathrm{P}<0.05)$

for extraction with $80 \%$ ethanol (18.46\%), while extraction with $100 \%$ methanol resulted in the lowest extraction yield $(13.84 \%)$. In our study extraction with methanol achieved higher yield compared to the other solvents. Similarly, Zahoor et al. (2016) obtained the highest yield (44.24 g/100g) of C. reticulata "Merisol" peel extracted by pure methanol compared to other solvents and solvent mixtures. Plants are an important source of potentially bioactive compounds for the development of new chemotherapeutic agents. Numerous studies have shown that the bioactivities of the plant extracts are mainly due to the presence of phenolic compounds. The results of TPC are presented in Table 1 . The acetonic extract of L. nobilis collected in Lastva showed the highest TPC $(83.84 \mathrm{mg}$ $\mathrm{GAE} / \mathrm{g}$ ), but also the commercial extract was rich in phenolics $(75.98 \mathrm{mg} \mathrm{GAE} / \mathrm{g})$. Acetonic extracts of O. basilicum and water extracts of $C$. reticulata peel had the lowest TPC. Statistical analysis of the obtained results indicates that the origin of the plant material in most cases, as well as the applied solvent, have influence on TPC (Table 1). Javanmardi et al. (2003) tested a number of acetonic extracts of $O$. basilicum from different localities in Iran and found that the TPC ranged from 23.00 to $65.50 \mathrm{mg}$ GAE/g, while in our study commercial O. basilicum acetone extract and $O$. basilicum from Lastva had 28.52 and $25.45 \mathrm{mg} \mathrm{GAE} / \mathrm{g}$, respectively. Ahmed et al. (2019) obtained different amounts of TPC in the study of ethanolic extracts of leaves and stems of basil collected from different locations in Egypt and concluded that this difference may be due to various climatic, seasonal and geographical conditions of the locations. Such dissimilarities can be also noticed in our results among samples of different origin. Kivrak et al. (2017) analyzed four L. nobilis leaves extracts and found higher TPC in ethanolic extract compared to water extract. Their findings are similar to the results obtained in this research, where methanolic extracts showed higher TPC compared to water ones. On the other hand, water extract of bay leaves collected in Morocco contained the highest TPC compared to other solvents (Taroq et al., 2018). Muñiz-Márquez et al. (2014) analyzed the effect of extraction time and different ethanol concentrations on the yields of polyphenols in bay leaves. The values for TPC were observed to grow with the increase of percentage of ethanol compared to water extract. In our study, the ace- tonic extracts of $C$. reticulata had the highest TPC, while in the study of Zahoor et al. (2016) and Safdar et al. (2017) maximum polyphenols were extracted with methanol. Zhang et al. (2014) analyzed phenolic compounds in the $80 \%$ methanolic extracts of peels of 14 wild mandarin genotypes native to China, and obtained TPC ranging from 29.38 to $51.14 \mathrm{mg} \mathrm{GAE} / \mathrm{g}$. Zhang et al. (2018) have analyzed methanolic extracts of nineteen $C$. reticulata genotypes and found that TPC varied from 22.80 to $32.76 \mathrm{mg} \mathrm{GAE} / \mathrm{g}$, while our results ranged from 34.62 to 43.00 $\mathrm{mg} \mathrm{GAE} / \mathrm{g}$.

The results of TFC are presented in Table 1. Both acetonic extracts of $O$. basilicum were rich in flavonoids, especially the sample from Lastva (44.83 $\mathrm{mg} \mathrm{QE} / \mathrm{g})$. Generally, C. reticulata peel extracts showed the lowest values of TFC $(6.09-13.61 \mathrm{mg}$ $\mathrm{QE} / \mathrm{g})$. The origin of plant material had statistically significant impact in the case of O. basilicum and L. nobilis, while the effect of the used solvent was statistically significant for majority of samples (Table 1). Kaurinović et al. (2011) found considerably high TFC in water extracts of $O$. basilicum leaves, $26.42 \mu \mathrm{g}$ RE/g. In their research, Kivrak et al. (2017) have found that ethanolic extract of L. nobilis possess higher TFC than water extract, which is similar to our results, with noticeable higher TFC in methanolic extracts. Likewise, the ethanolic extract of bay leaves from Morocco had the highest TFC (Taroq et al., 2018). Zhang et al. (2014) notified that TFC varied from 6.28 to $20.66 \mathrm{mg} \mathrm{RE} / \mathrm{g}$ for methanolic extracts of peels of Chinese mandarin genotypes. Zhang et al. (2018) have found that TFC for Chinese $C$. reticulata methanolic extracts ranged from 23.29 to $56.52 \mathrm{mg} \mathrm{RE} / \mathrm{g}$, which was evidently higher compared to our results (6.34-8.05 mg QE/g). Generally, literature data demonstrate that the TPC and TFC vary depending on the locality, season, applied solvent and the extraction procedure (Javanmardi et al., 2003; Kivrak et al., 2017; Muñiz-Márquez et al., 2014; Safdar et al., 2017). In our study (Table 1) the statistical analysis showed that the sample origin had a significant influence on both TPC and TFC. The used solvent had statistically significant impact to TPC and TFC in majority of tested extracts. 
Table 2. The activity of the plant extracts (at the concentration of $0.5 \mathrm{mg} / \mathrm{mL}$ ) and standards (at the concentration of 0.1 $\mathrm{mg} / \mathrm{mL}$ ) against DPPH radical and the total reducing power activity (TRP).

\begin{tabular}{|c|c|c|c|c|c|c|c|}
\hline \multirow[t]{3}{*}{ Species } & \multirow[t]{3}{*}{ Extract type } & \multicolumn{2}{|c|}{$\mathrm{DPPH}^{\mathrm{a}}$} & \multicolumn{4}{|c|}{ TRP } \\
\hline & & \multicolumn{2}{|c|}{ [\%] } & \multicolumn{4}{|c|}{$[\mu \mathrm{mol} \mathrm{AAE} / \mathrm{g}]$} \\
\hline & & Commercial & Lastva & & Commercial & Lastva & \\
\hline \multirow[t]{3}{*}{ O. basilicum } & Acetonic & $15.74 \pm 1.25 \mathrm{~g}$ & $23.82 \pm 1.73 \mathrm{~h}$ & & $349.06 \pm 3.19 \mathrm{e}$ & $344.82 \pm 10.72 \mathrm{~d}$ & \\
\hline & Methanolic & $36.14 \pm 1.54 \mathrm{f}$ & $33.92 \pm 0.87 \mathrm{fg}$ & & $582.70 \pm 4.10 \mathrm{~d}$ & $454.52 \pm 7.73 c$ & $\dagger$ \\
\hline & Aqueous & $52.67 \pm 1.48 \mathrm{~d}$ & $65.26 \pm 2.72 c$ & & $629.97 \pm 2.29 c$ & $668.45 \pm 12.73 b$ & $\dagger$ \\
\hline \multirow[t]{3}{*}{ L. nobilis } & Acetonic & $79.71 \pm 3.15 b$ & $85.87 \pm 2.54 b$ & & $765.42 \pm 2.29 \mathrm{a}$ & $792.70 \pm 22.27 \mathrm{a}$ & \\
\hline & Methanolic & $78.41 \pm 4.08 \mathrm{~b}$ & $47.57 \pm 1.08 \mathrm{~d}$ & $t$ & $689.97 \pm 5.25 b$ & $481.18 \pm 15.45 c$ & $\dagger$ \\
\hline & Aqueous & $59.89 \pm 2.16 c$ & $30.08 \pm 1.64 \mathrm{~g}$ & $t$ & $681.79 \pm 18.92 b$ & $353.91 \pm 11.82 \mathrm{~d}$ & $\dagger$ \\
\hline \multirow[t]{3}{*}{ C. reticulata } & Acetonic & $9.79 \pm 0.06 \mathrm{~h}$ & $12.70 \pm 0.26 \mathrm{i}$ & & $194.21 \pm 8.15 \mathrm{~g}$ & $184.82 \pm 12.73 \mathrm{e}$ & \\
\hline & Methanolic & $8.21 \pm 1.58 \mathrm{~h}$ & $8.08 \pm 0.59 \mathrm{j}$ & & $137.55 \pm 8.33 \mathrm{~h}$ & $166.03 \pm 8.40 \mathrm{e}$ & $\dagger$ \\
\hline & Aqueous & $16.02 \pm 0.31 \mathrm{~g}$ & $9.31 \pm 0.06 \mathrm{ij}$ & & $256.03 \pm 2.29 \mathrm{f}$ & $199.06 \pm 13.65 \mathrm{e}$ & $\dagger$ \\
\hline \multirow[t]{3}{*}{ Standards } & Ascorbic acid & $91.65 \pm 0.21 \mathrm{a}$ & $91.65 \pm 0.21 \mathrm{a}$ & & - & - & \\
\hline & BHA & $43.33 \pm 0.87 \mathrm{e}$ & $43.33 \pm 0.87 \mathrm{e}$ & & - & - & \\
\hline & $\mathrm{BHT}$ & $34.31 \pm 0.43 \mathrm{f}$ & $34.31 \pm 0.43 \mathrm{f}$ & & - & - & \\
\hline
\end{tabular}

${ }^{a}$ Different letters denote statistical difference among means according to post-hoc Tuckey HSD test at level $\mathrm{P}<0.05$.

$\mathrm{b}+$ sign denote statistically significant difference between Commercial and Lastva mean values according to the Student's $t$-test $(\mathrm{P}<0.05)$.

\subsection{Antioxidant activity}

The antioxidant activity was evaluated applying DPPH assay which has been widely used for the determination of free radical scavenging capacity of samples and total reducing power assay (TRP) which evaluates potential of sample to reduce potassium ferricyanide $\left(\mathrm{Fe}^{3+}\right)$ to form potassium ferrocyanide $\left(\mathrm{Fe}^{2+}\right)$. The results for antioxidant activity are presented in the Table 2. Acetonic extracts of leaves of L. nobilis showed the highest antioxidant activity in both assays. Likewise, water extracts of $O$. basilicum leaves exhibited high antioxidant potential. The influence of the solvent was statistically significant in both applied assays. The origin of the plant material was statistically significant in TRP assay for all species, while in DPPH test only in the case of L. nobilis.

Kaurinović et al. (2011) have obtained the best results in $\mathrm{DPPH}$ assay among the investigated extracts for water one of $O$. basilicum, which is in accordance with our results. Zakaria et al. (2008) showed that methanolic extracts of $O$. basilicum leaves inhibited $45.35 \%$ of DPPH radical at the concentration of $1 \mathrm{mg} / \mathrm{mL}$, while in our study, commercial $O$. basilicum methanolic extract achieved $36.14 \%$, and cultivated O. basilicum methanolic extract $33.92 \%$ at the concentration of $0.5 \mathrm{mg} / \mathrm{mL}$. In the research of Ahmed et al. (2019) ethanol extracts of basil from different locations exhibited stronger radical scavenging activity than that of synthetic antioxidant BHT, while in our study standards were significantly stronger than extracts in applied concentrations. Antioxidant activity study of Kivrak et al. (2017) showed that water extract of $L$. nobilis had rather lower activity in all the applied assays compared to ethanolic extracts. Their findings are in accordance with our results for both used methods. Methanolic extract of L. nobilis possessed effective reducing power in the study of Pacifico et al. (2014), while in our research it was less potent comparing to acetonic extract. Water extract of Moroccan bay leaves exhibited the highest DPPH radical scavenging activity comparing to other tested extracts, which was probably due to its high content of phenols (Taroq et al., 2018). Our results showed higher antioxidant activity of acetonic extracts than methanolic extracts. Dias et al. (2014) compared leaves of wild and cultivated L. nobilis plants and found that infusions of both samples revealed higher antioxidant activity than methanolic extracts, while in our study the methanolic extracts exhibited higher DPPH activity compared to water extracts. Water extract of Portuguese L. nobilis showed DPPH activity of $61 \%$ (Ferreira et al., 2006), similar as it was obtained in our research for commercial sample (59.89\%) at the same concentration. Antioxidant activity of mandarin peels was studied by Xu et al. (2008) and they concluded that hot water extraction was effective in extracting of antioxidant compounds in Citrus peels, which was also the case in our study, with the highest antioxidant capacity obtained for the water extract of commercial sample (16.02\%). Chen et al. (2011) have obtained considerably better results for ethanolic $C$. reticulata peel extract compared to our results. Zahoor et al. (2016) and Safdar et al. (2017) demonstrated high efficiency of methanolic extracts of $C$. reticulata from Pakistan, while methanolic extracts in our research had the lowest antioxidant activity. Zhang et al. (2014) reported that the DPPH values of the methanolic extracts of wild mandarins peel varied from 29.04 to 50.46 $\mu \mathrm{mol}$ Trolox equivalents/g. The FRAP values of the 14 wild mandarins, obtained by $\mathrm{Fe}^{3+}$ reduction assay similar to TRP used in this research, ranged from 26.50 to $46.98 \mu \mathrm{mol}$ TE/g DW in the study of Zhang et al. (2014).

\subsection{Antineurodegenerative activity}

The analysis of potential antineurodgenerative activity of various extracts of leaves and mandarin peel was conducted and the results of inhibition of acetycholinesterase, which is therapeutic target for $\mathrm{AD}$, are presented in Table 3. The highest AChE inhibition was achieved by water extract of commercial L. nobilis, followed by acetonic and methanolic extracts. Among tested samples of $O$. basilicum, methanolic extracts 
Table 3. The inhibition of $\alpha$-glucosidase and acetylcholinesterase (AChE) tested on plant extracts (at the concentration of $0.5 \mathrm{mg} / \mathrm{mL}$ ) and standards (at the concentration of $0.1 \mathrm{mg} / \mathrm{mL}$ ).

\begin{tabular}{|c|c|c|c|c|c|c|c|}
\hline \multirow[t]{3}{*}{ Species } & \multirow[t]{3}{*}{ Extract type } & \multicolumn{2}{|c|}{$\alpha$-glucosidase $\mathrm{e}^{\mathrm{a}, \mathrm{b}}$} & \multicolumn{4}{|c|}{$\mathrm{AChE}$} \\
\hline & & \multicolumn{2}{|c|}{ Enzyme inhibition [\%] } & \multicolumn{4}{|c|}{ Enzyme inhibition [\%] } \\
\hline & & Commercial & Lastva $^{c}$ & & Commercial & Lastva & \\
\hline \multirow[t]{3}{*}{ O. basilicum } & Acetonic & $44.83 \pm 0.88 b$ & $6.25 \pm 0.68 \mathrm{~d}$ & $\dagger$ & $47.68 \pm 4.66 c$ & $28.74 \pm 1.26 \mathrm{e}$ & $\dagger$ \\
\hline & Methanolic & $12.42 \pm 2.31 \mathrm{~d}$ & $13.65 \pm 4.36 \mathrm{c}$ & & $51.30 \pm 5.27 c$ & $43.71 \pm 3.67 \mathrm{~d}$ & \\
\hline & Aqueous & n.d. & $86.48 \pm 1.02 \mathrm{~b}$ & $\dagger$ & $29.14 \pm 3.08 \mathrm{~d}$ & n.d. & + \\
\hline \multirow[t]{3}{*}{ L. nobilis } & Acetonic & $23.72 \pm 3.88 c$ & $92.52 \pm 4.35 \mathrm{ab}$ & + & $82.61 \pm 3.10 \mathrm{~b}$ & $55.77 \pm 4.11 \mathrm{c}$ & $\dagger$ \\
\hline & Methanolic & $48.83 \pm 1.48 b$ & $89.97 \pm 0.53 \mathrm{ab}$ & + & $80.16 \pm 4.05 b$ & $73.99 \pm 1.18 b$ & \\
\hline & Aqueous & n.d. & $11.10 \pm 1.68 \mathrm{~cd}$ & + & $90.72 \pm 4.01 \mathrm{ab}$ & $46.60 \pm 0.36 \mathrm{~d}$ & + \\
\hline \multirow[t]{3}{*}{ C. reticulata } & Acetonic & n.d. & n.d. & & $18.69 \pm 4.77 \mathrm{~d}$ & $21.23 \pm 2.12 \mathrm{f}$ & \\
\hline & Methanolic & n.d. & n.d. & & $25.07 \pm 3.90 \mathrm{~d}$ & $8.34 \pm 2.94 \mathrm{~g}$ & $\dagger$ \\
\hline & Aqueous & n.d. & n.d. & & $46.12 \pm 2.48 \mathrm{c}$ & $22.44 \pm 0.34$ ef & + \\
\hline \multirow[t]{2}{*}{ Standards } & Acarbose & $95.51 \pm 0.86 \mathrm{a}$ & $95.51 \pm 0.86 \mathrm{a}$ & & - & - & \\
\hline & Galantamine & - & - & & $96.12 \pm 0.96 \mathrm{a}$ & $96.12 \pm 0.96 \mathrm{a}$ & \\
\hline
\end{tabular}

showed higher activity compared to other extracts, while the mandarin peel was the most effective in the water extracts (Table 3). The AChE inhibition was significantly affected by both plant origin and the extraction solvent. Pharmacological studies on $O$. basilicum have demonstrated potent antioxidant activities with some reports of neuroprotective actions (Manali et al., 2018). Basil essential oils were much more investigated for AChE inhibition than its extracts. The results of Sarahroodi et al. (2012) indicated that $80 \%$ ethanolic extract of $O$. basilicum significantly increased memory retention and retrieval of mice. Among ethanolic and water extracts of ten Portuguese plants analyzed by Ferreira et al. (2006), L. nobilis showed AChE inhibitory activity of $19.9 \%$ for water extract, but much higher for ethanolic extract $(48.4 \%)$ using concentrations of $0.5 \mathrm{mg} / \mathrm{mL}$. In our research at the same concentration, the commercial L. nobilis displayed higher activity of water extract $(90.72 \%)$ comparing to methanolic and acetonic extracts. Senol et al. (2016) in their study of ethanolic extracts of peels of 17 Turkish Citrus cultivars notified that extracts at the concentration of $0.5 \mathrm{mg} / \mathrm{mL}$ did not affect AChE activity, while in our study, at the same concentration, the mandarin peels showed AChE inhibition ranging from 8.34 to $46.12 \%$. El-Khadragy et al. (2014) tested the methanolic extract of mandarin peel on memory impairment in rats produced by scopolamine, and concluded that administration of mandarin peel extract may be of value for dementia exhibiting elevated brain oxidative status.

\subsection{Antidiabetic activity}

Diabetes mellitus has been proved to be linked to cognitive decline and neurodegeneration in general. Alpha glucosidase inhibitors delay carbohydrate absorption in the gastrointestinal tract, control postprandial hyperglycaemia and reduce the risk of cardiovascular and neurological complications in the development of the disease (Kalra, 2014). The results of $\alpha$-glucosidase inhibition are presented in the Table 3. The best results were obtained for water extract of $O$. basilicum and acetonic and methanolic extracts for L. nobilis originated from Lastva. The inhibition was not detected for the C. reticulata peels. Origin of the plant material and applied solvent significantly affected the $\alpha$-glucosidase inhibition in the case of $O$. basilicum and L. nobilis (Table 3). Malapermal et al. (2017) showed that $O$. basilicum ethanolic extracts $(70 \%$ and $60 \%$ ethanol) had higher antidiabetic activity than aqueous extract, which is similar to our results in the case of commercial sample. However, aqueous extract of $O$. basilicum from Lastva had the third best activity of all of the tested samples, which was far higher than the activity of the methanolic extract. The majority of data on the $\alpha$-glucosidase inhibitory activity of L. nobilis is regarding to the essential oil, while the information on extracts is scarce. However, Kazeem et al. (2016) tested acetone extracts of bay leaves which displayed high antiglycation and antioxidant potential. Indrianingsih et al. (2015) have found that $L$. nobilis methanolic extract at the concentration of 0.2 $\mathrm{mg} / \mathrm{mL}$ inhibited $47.26 \% \alpha$-glucosidase, which is in agreement with the results obtained in this study for the cultivated L. nobilis. Fayek et al. (2017) investigated the antidiabetic potency of different Citrus peel extracts and showed that mandarin peels decreased the glucose level in rats. Oboh and Ademosun (2011) found that $\alpha$-glucosidase inhibitory effect of the Shaddock (Citrus maxima) peel acetonic extract achieved 89.05\% at the tested concentration of $0.32 \mathrm{mg} / \mathrm{mL}$. The enzymatic activity of $\alpha$-glucosidase was tested for Citrus limetta peel extract and was found that at the lowest tested concentration $(1.125 \mathrm{mg} / \mathrm{mL}$ ) 5.2\% enzyme was inhibited (Padilla-Camberos et al., 2014). It is considered that dietary $\alpha$-glucosidase natural inhibitors are safe to control hyperglycemia, and medicinal plants could be useful remedies in treatment of diabetes and other health disorders (El-Beshbishy and Bahashwan, 2012).

\subsection{Correlation between antioxidant activities, enzyme inhi- bition and total phenolic and flavonoid content}

Pearson's correlation coefficients were calculated between total phenolic and flavonoid contents of tested extracts and their 
antioxidant activities and $\alpha$-glucosidase (AGLU) and AChE inhibition (Table 4). Antioxidant activity was more strongly correlated to total phenolic than total flavonoid content which is in accordance to Wojdylo et al. (2007). Antioxidant potential of the plant material usually correlates well with the phenolic content, which was also the case in the study of different extracts from fresh, frozen and lyophilized basil leaves (Złotek et al., 2016), where the correlation between phenolic content and antioxidant activity was positive and varied regarding to the used material. TPC displayed moderate correlation to AGLU and AChE inhibition activities. Polyphenols seem to be mostly involved in antioxidant activity and enzyme inhibition thereby possessing therapeutic potential for AD and DM. Antioxidant assays were strongly correlated to AChE inhibition, and moderately to $\alpha$-glucosidase inhibition, while the enzyme inhibition tests were moderately correlated.

Table 4. Linear correlation between the assays used for analysis of the TPC and TFC, antioxidant activity and enzyme inhibition.

\begin{tabular}{lcccccc} 
& TPC $^{\mathrm{a}}$ & TFC & DPPH & TRP & AGLU & AChE \\
\hline TPC & 1 & $-0.17^{\mathrm{A}}$ & $0.83^{\mathrm{C}}$ & $0.73^{\mathrm{C}}$ & $0.58^{\mathrm{B}}$ & $0.51^{\mathrm{B}}$ \\
TFC & & 1 & $0.03^{\mathrm{A}}$ & $0.12^{\mathrm{A}}$ & $-0.12^{\mathrm{A}}$ & $0.01^{\mathrm{A}}$ \\
DPPH & & & 1 & $0.96^{\mathrm{C}}$ & $0.54^{\mathrm{B}}$ & $0.78^{\mathrm{C}}$ \\
TRP & & & & 1 & $0.47^{\mathrm{B}}$ & $0.78^{\mathrm{C}}$ \\
AGLU & & & & & 1 & $0.46^{\mathrm{B}}$ \\
AChE & & & & & & 1
\end{tabular}

a Different letters denote estimation of the correlation strength according to Taylor $(1990)$, where A $(r<0.35), B(0.36<r<0.67)$ and C $(0.68<r<1)$ were considered weak, moderate and strong correlation, respectively.

\section{CONCLUSION}

Among tested samples, O. basilicum and L. nobilis cultivated in Montenegro had higher level of antioxidant activity in both assays and also of $\alpha$-glucosidase inhibition, while water extract of commercial L. nobilis had the highest AChE inhibition. The commercial sample of $C$. reticulata peel exhibited slightly better antioxidant and $\mathrm{AChE}$ inhibition activities. The origin of plant material was statistically significant in the majority of applied assays. The applied solvent was statistically significant in most cases, probably due to differences in the chemical composition of the extracts. The acetonic extract of $L$. nobilis had the highest TPC and also provided the best results in antioxidant tests. Since the acetonic extract of $L$. nobilis from Lastva showed the highest TPC, antioxidant activity and $\alpha$ glucosidase inhibition, and water extract of commercial $L$. nobilis exhibited the highest AChE inhibition, the bay leaves could be promising antioxidant, antineurodegenerative and antidiabetic agent.

\section{ACKNOWLEDGMENTS}

This work was supported by the Ministry of Education, Science and Technological Development of the Republic of Serbia, Project No. 173029.

\section{REFERENCES}

Ahmad, W., Ijaz, B., Shabbiri, K., Ahmed, F. and Rehman, S. (2017). Oxidative toxicity in diabetes and Alzheimer's disease: mechanisms behind ROS/ RNS generation, Journal of Biomedical Science 24(1): 76.
Ahmed, A. F., Attia, F. A., Liu, Z., Li, C., Wei, J. and Kang, W. (2019). Antioxidant activity and total phenolic content of essential oils and extracts of sweet basil (Ocimum basilicum L.) plants, Food Science and Human Wellness 8(3): 299-305.

Barla, A., Topcu, G., Oksuz, S., Tumen, G. and Kingston, D. (2007). Identification of cytotoxic sesquiterpenes from Laurus nobilis L., Food Chemistry 104(4): 1478-1484.

Bazzari, A. H. and Bazzari, F. H. (2018). Medicinal plants for Alzheimer's disease: An updated review, Journal of Medicinal Plants Studies 6(2): 81-85.

Bomma, M., Okafor, F., Mentreddy, S., Nyochembeng, L., Setzer, W. and Vogler, B. (2018). Comparison of methods of extraction and antimicrobial activity of six Ocimum species against human pathogens, Journal of Agriculture E Life Sciences $5(2)$.

Chen, X. T., Jiang, D. Q., Chen, F. F. and Yuan, K. (2011). Investigation of active components and antioxidant activities in peel and pulp extracts of Citrus reticulata Blanco cv. Suavissima fruit, Advanced Materials Research 343-344: 1098-1102.

Dias, M. I., Barreira, J. C. M., Calhelha, R. C., Queiroz, M.-J. R. P., Oliveira, M. B. P. P., Soković, M. and Ferreira, I. C. F. R. (2014). Two-dimensional PCA highlights the differentiated antitumor and antimicrobial activity of methanolic and aqueous extracts of Laurus nobilis L. from different origins, BioMed Research International 2014: 1-10.

El-Beshbishy, H. and Bahashwan, S. (2012). Hypoglycemic effect of basil (Ocimum basilicum) aqueous extract is mediated through inhibition of $\alpha$-glucosidase and $\alpha$-amylase activities: An in vitro study, Toxicology and Industrial Health 28(1): $42-50$.

El-Khadragy, M., Al-Olayan, E. and Moneim, A. (2014). Neuroprotective effects of Citrus reticulata in scopolamine-induced dementia oxidative stress in rats, CNS $\mathcal{E}$ Neurological Disorders - Drug Targets 13(4): 684-690.

Ellman, G. L., Courtney, K., Andres, V. and Featherstone, R. M. (1961). A new and rapid colorimetric determination of acetylcholinesterase activity, Biochemical Pharmacology 7(2): 88-95.

Fayek, N. M., El-Shazly, A. H., Abdel-Monem, A. R., Moussa, M. Y., Abd-Elwahab, S. M. and El-Tanbouly, N. D. (2017). Comparative study of the hypocholesterolemic, antidiabetic effects of four agro-waste Citrus peels cultivars and their HPLC standardization, Revista Brasileira de Farmacognosia 27(4): 488-494.

Ferreira, A., Proença, C., Serralheiro, M. and Araújo, M. (2006). The in vitro screening for acetylcholinesterase inhibition and antioxidant activity of medicinal plants from Portugal, Journal of Ethnopharmacology 108(1): 31-37.

Garg, S. N., Siddiqui, M. S. and Agarwal, S. K. (1992). New fatty acid esters and hydroxy ketones from fruits of Laurus nobilis, Journal of Natural Products 55(9): 1315-1319.

Grayer, R. J., Bryan, S. E., Veitch, N. C., Goldstone, F. J., Paton, A. and Wollenweber, E. (1996). External flavones in sweet basil, Ocimum basilicum, and related taxa, Phytochemistry 43(5): 1041-1047.

Hamid, A. A., Aiyelaagbe, O. O., Usman, L. A., Ameen, O. M. and Lawal, A. (2010). Antioxidants: Its medicinal and pharmacological applications, African Journal of Pure and Applied Chemistry 4(8): 142-151. 
Indrianingsih, A. W., Tachibana, S. and Itoh, K. (2015). In vitro evaluation of antioxidant and $\alpha$-glucosidase inhibitory assay of several tropical and subtropical plants, Procedia Environmental Sciences 28: 639-648.

Javanmardi, J., Stushnoff, C., Locke, E. and Vivanco, J. (2003). Antioxidant activity and total phenolic content of Iranian Ocimum accessions, Food Chemistry 83(4): 547-550.

Kalra, S. (2014). Alpha glucosidase inhibitors, JPMA. The Journal of the Pakistan Medical Association 64(4): 474-476.

Kaurinović, B., Popović, M., Vlaisavljević, S. and Trivić, S. (2011). Antioxidant capacity of Ocimum basilicum L. and Origanum vulgare L. extracts, Molecules 16(9): 7401-7414.

Kazeem, M. I., Ashafa, A. O. T. and Nafiu, M. O. (2016). Biological activities of three Nigerian Spices - Laurus nobilis Linn, Murraya koenigii (L) Spreng and Thymus vulgaris Linn, Tropical Journal of Pharmaceutical Research 14(12): 2255.

Kivrak, e., Göktürk, T. and Kivrak, b. (2017). Assessment of volatile oil composition, phenolics and antioxidant activity of bay (Laurus nobilis) leaf and usage in cosmetic applications, International Journal of Secondary Metabolite pp. 148148.

Maajida Aafreen M, Geetha RV and Lakshmi Thangavelu (2019). Evaluation of anti-inflammatory action of Laurus nobilis - an in vitro study of anti-inflammatory action, International Journal of Research in Pharmaceutical Sciences 10(2): 12091213.

Malapermal, V., Botha, I., Krishna, S. B. N. and Mbatha, J. N. (2017). Enhancing antidiabetic and antimicrobial performance of Ocimum basilicum, and Ocimum sanctum (L.) using silver nanoparticles, Saudi Journal of Biological Sciences 24(6): 1294-1305.

Manali, H., Juriyati, J., Chan, K. and Norazrina, A. (2018). A brief review of potential neuroprotective roles of the culinary herb Ocimum basilicum, Medicine $\mathcal{E}$ Health 13(2): 3-19.

Muñiz-Márquez, D., Rodríguez, R., Balagurusamy, N., Carrillo, M., Belmares, R., Contreras, J., Nevárez, G. and Aguilar, C. (2014). Phenolic content and antioxidant capacity of extracts of Laurus nobilis L., Coriandrum sativum L. and Amaranthus hybridus L., CyTA - Journal of Food 12(3): 271-276.

Nasri, H., Shirzad, H., Baradaran, A. and Rafieian-Kopaei, M. (2015). Antioxidant plants and diabetes mellitus, Journal of Research in Medical Sciences 20(5): 491-502.

Nogata, Y., Sakamoto, K., Shiratsuchi, H., Ishii, T., Yano, M. and Ohta, H. (2006). Flavonoid composition of fruit tissues of Citrus species, Bioscience, Biotechnology, and Biochemistry 70(1): 178-192.

Oboh, G. and Ademosun, A. O. (2011). Shaddock peels (Citrus maxima) phenolic extracts inhibit $\alpha$-amylase, $\alpha$-glucosidase and angiotensin I-converting enzyme activities: A nutraceutical approach to diabetes management, Diabetes $\mathcal{E}$ Metabolic Syndrome: Clinical Research \& Reviews 5(3): 148-152.

Pacifico, S., Gallicchio, M., Lorenz, P., Duckstein, S. M., Potenza, N., Galasso, S., Marciano, S., Fiorentino, A., Stintzing, F. C. and Monaco, P. (2014). Neuroprotective potential of Laurus nobilis antioxidant polyphenol-enriched leaf extracts, Chemical Research in Toxicology 27(4): 611-626.
Padilla-Camberos, E., Lazcano-Díaz, E., Flores-Fernandez, J. M., Owolabi, M. S., Allen, K. and Villanueva-Rodríguez, S. (2014). Evaluation of the inhibition of carbohydrate hydrolyzing enzymes, the antioxidant activity, and the polyphenolic content of Citrus limetta peel extract, The Scientific World Journal 2014: 1-4.

Purushothaman, B., Prasanna Srinivasan, R., Suganthi, P., Ranganathan, B., Gimbun, J. and Shanmugam, K. (2018). A Comprehensive Review on Ocimum basilicum, Journal of Natural Remedies 18(3): 71-85.

Reddy, V. P., Zhu, X., Perry, G. and Smith, M. A. (2009). Oxidative stress in diabetes and Alzheimer's disease, Journal of Alzheimer's Disease 16(4): 763-774.

Safdar, M. N., Kausar, T., Jabbar, S., Mumtaz, A., Ahad, K. and Saddozai, A. A. (2017). Extraction and quantification of polyphenols from kinnow (Citrus reticulate L.) peel using ultrasound and maceration techniques, Journal of Food and Drug Analysis 25(3): 488-500.

Sarahroodi, S., Esmaeili, S., Hemmati, Z., Mikaili, P. and Saberi, Y. (2012). The effects of green Ocimum basilicum hydroalcoholic extract on retention and retrieval of memory in mice, Ancient Science of Life 31(4): 185.

Senol, F., Ankli, A., Reich, E. and Orhan, I. (2016). HPTLC finger-printing and cholinesterase inhibitory and metalchelating capacity of various Citrus cultivars and Olea europaea, Food Technology and Biotechnology 54(3).

Singleton, V. L. and Rossi, J. A. (1965). Colorimetry of total phenolics with phosphomolybdic-phosphotungstic acid reagents, American Journal of Enology and Viticulture 16(3): 144-158.

Taroq, A., El Kamari, F., Aouam, I., El Atki, Y., Lyoussi, B. and Abdellaoui, A. (2018). Antioxidant activities and total phenolic and flavonoid content variations of leaf extracts of Laurus nobilis L. from Morocco, Asian Journal of Pharmaceutical and Clinical Research 11(12): 540.

Taylor, R. (1990). Interpretation of the correlation coefficient: A basic review, Journal of Diagnostic Medical Sonography 6(1): 3539.

Toth, C. (2014). Diabetes and neurodegeneration in the brain, Handbook of Clinical Neurology, Vol. 126, Elsevier, pp. 489511.

Trivellini, A., Lucchesini, M., Maggini, R., Mosadegh, H., Villamarin, T. S. S., Vernieri, P., Mensuali-Sodi, A. and Pardossi, A. (2016). Lamiaceae phenols as multifaceted compounds: bioactivity, industrial prospects and role of "positive-stress", Industrial Crops and Products 83: 241-254.

Tumbas, V., Ćetković, G., Đilas, S., Čanadanović Brunet, J., Vulić, J., Knez, e. and Škerget, M. (2010). Antioxidant activity of mandarin (Citrus reticulata) peel, Acta periodica technologica (41): 195-203.

Tusevski, O., Kostovska, A., Iloska, A., Trajkovska, L. and Simic, S. (2014). Phenolic production and antioxidant properties of some Macedonian medicinal plants, Open Life Sciences 9(9).

Wan, L.-S., Min, Q.-X., Wang, Y.-L., Yue, Y.-D. and Chen, J.-C. (2013). Xanthone glycoside constituents of Swertia kouitchensis with $\alpha$-glucosidase inhibitory activity, Journal of Natural Products 76(7): 1248-1253. 
Wojdylo, A., Oszmianski, J. and Czemerys, R. (2007). Antioxidant activity and phenolic compounds in 32 selected herbs, Food Chemistry 105(3): 940-949.

Xu, G., Chen, J., Liu, D., Zhang, Y., Jiang, P. and Ye, X. (2008). Minerals, phenolic compounds, and antioxidant capacity of Citrus peel extract by hot water, Journal of Food Science 73(1): C11-C18.

Xu, G., Ye, X., Chen, J. and Liu, D. (2007). Effect of heat treatment on the phenolic compounds and antioxidant capacity of Citrus peel extract, Journal of Agricultural and Food Chemistry 55(2): 330-335.

Zahoor, S., Anwar, F., Mehmood, T., Sultana, B. and Qadir, R. (2016). Variation in antioxidant attributes and individual phenolics of citrus fruit peels in relation to different species and extraction solvents, Journal of the Chilean Chemical Society 61(2): 2884-2889.

Zakaria, Z., Aziz, R., Lachimanan, Y. L., Sreenivasan, S. and Rathinam, X. R. (2008). Antioxidant activity of Coleus blumei, Orthosiphon stamineus, Ocimum basilicum and Mentha arvensis from Lamiaceae family, International Journal of Natural and Engineering Sciences 2(1): 93-95.

Zhang, H., Yang, Y.-f. and Zhou, Z.-q. (2018). Phenolic and flavonoid contents of mandarin (Citrus reticulata Blanco) fruit tissues and their antioxidant capacity as evaluated by DPPH and ABTS methods, Journal of Integrative Agriculture 17(1): 256-263.

Zhang, Y., Sun, Y., Xi, W., Shen, Y., Qiao, L., Zhong, L., Ye, X. and Zhou, Z. (2014). Phenolic compositions and antioxidant capacities of Chinese wild mandarin (Citrus reticulata Blanco) fruits, Food Chemistry 145: 674-680.

Złotek, U., Mikulska, S., Nagajek, M. and Świeca, M. (2016). The effect of different solvents and number of extraction steps on the polyphenol content and antioxidant capacity of basil leaves (Ocimum basilicum L.) extracts, Saudi Journal of Biological Sciences 23(5): 628-633. 